\title{
SỰ THỐNG NHẤT GIỮA TIINH CHÍNH TRI VÀ TÍNH NHÂN VĂN TRONG CON ĐƯỜNG CÁCH MẠNG MÀ CHƯ TIICH HỒ CHÍ MINH ĐÃ LỰA CHỌN
}

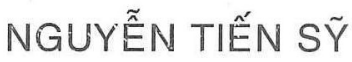

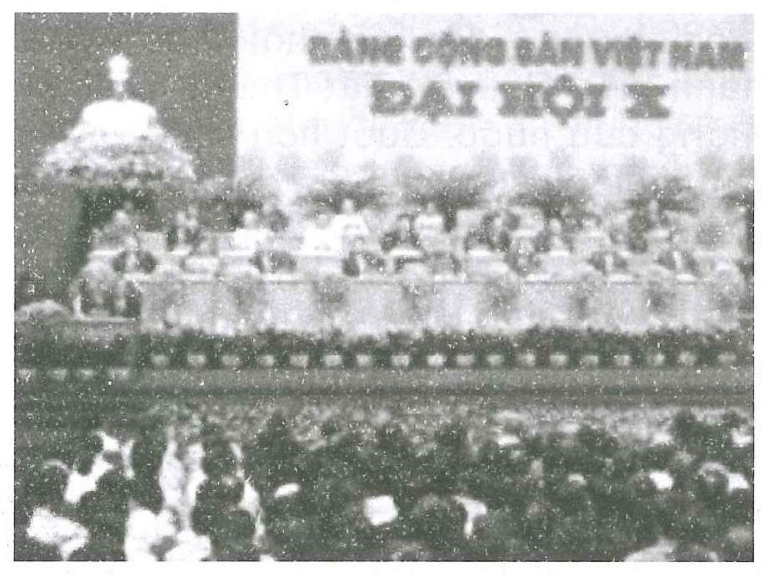

Chủ tịch Hồ Chí Minh là lãnh tụ vĩ đại của giai cấp công nhân và nhân dân lao động Việt Nam, anh hùng giải phóng dân tộc, nhà hoạt động chính trị lỗi lạc trong phong trào cộng sản công nhân quốc tế và danh nhân văn hóa thế giới. Toàn bộ di sản tư tưởng, đạo đức và phong cách của Người là những chuẩn mực giá trị để chúng ta học tập cho cuộc sống hôm nay và trên con đường đi tới xã hội tương lai. Con đường cách mạng mà Người đã lựa chọn chính là biểu tượng của những chuẩn mực giá trị đó, nó vừa đáp ứng được yêu cầu bức xúc của dân tộc, vừa là khát vọng của quần chúng cần lao sau bao đời phải cam chịu sống trong cảnh lầm than, đói khổ. Con

(*)TS. Đại tá Học viện Chính trị quân sự. đường cách mạng ở Việt Nam, con đường cách mạng vô sản phản ánh sự thống nhất giữa tính chính trị và tính nhân văn hết sức chặt chẽ và sâu sắc. Chính sự thống nhất ấy đã tạo nên nguồn sức mạnh vô địch của dân tộc ta trong sự nghiệp giải phóng dân tộc, thống nhất Tổ quốc. Ngày nay, trong sự nghiệp đổi mới toàn diện đất nước, việc kiên định con đường Chủ tịch Hồ Chí Minh đã lựa chọn, giữ vững định hướng xã hội chủ nghĩa trong phát triển nền kinh tế hàng hóa nhiều thành phần và $c o ̛$ chế thị trường có ý nghĩa sống còn đối với sự nghiệp cách mạng nước ta.

Lịch sử hàng ngàn năm qua của đất nước ta là lịch sử đấu tranh kiên cường và bền bỉ để giữ vững độc lập dân tộc. Trải qua biết bao thăng trầm đường cách mạng ở Việt Nam, con đường cách mạng vô sản phản ánh sự thống nhất giữa tính chính trị và tính nhân văn hết sức chặt chẽ và sâu sắc. Chính sự thống nhất ấy đã tạo nên nguồn sức mạnh vô địch của dân tộc ta trong sự nghiệp giải phóng dân tộc, thống nhất Tổ quốc. Ngày nay, trong sự nghiệp đổi mới toàn diện đất nước, việc kiên định con đường .Chủ tịch Hồ Chí Minh đã lựa chọn, giữ vững định hướng xã hội chủ nghĩa trong phát triển nền 
kinh tế hàng hóa nhiều thành phần và cơ chế thị trường có ý nghĩa sống còn đối với sự nghiệp cách mạng nước ta.

Lịch sử hàng ngàn năm qua của đất nước ta là lịch sử đấu tranh kiên cường và bền bỉ để giữ vững độc lập dân tộc. Trải qua biết bao thăng trầm lịch sử, bao biến cố hưng vong của các triều đại, nhân dân ta đã nhiều lần giành được độc lập dân tộc, nhưng rồi cũng nhiều phen lại rơi vào vòng nô lệ. Chính lòng căm thù quân xâm lược và nỗi xốt xa "thương cho cảnh nước mất nhà tan" đã thôi thúc nhân dân ta vùng dậy, viết lên những trang sử hào hùng làm ranng rỡ giống nòi. Niềm tự hào dân tộc, sẵn sàng xả thân vì độc lập dân tộc đã trở thành đạo lý sống của mỗi người dân Việt Nam ngay từ thuở các Vua Hùng dựng nước cho tới ngày nay.

Đất nước bị bọn xâm lược giày xéo thì không có khát vọng nào cao hơn là giành độc lập dân tộc. Nhưng không phải khi nào những người con yêu nước của dân tộc cũng tìm thấy cho mình một con đường cứu nước, cứu dân đúng đắn. Thực tiễn khi thực dân Pháp xâm lược nước ta cho đến những năm đầu thế kỷ $X X$ cho thấy, trước sức mạnh của thực dân Pháp, Nhà Nguyễn đã đầu hàng bán rẻ Tổ quốc, đất nước rơi vào tay thực dân Pháp. Nhân dân ta, các thế hệ nối tiếp nhau nhất tề đứng lên, mong đánh đổ thực dân Pháp, giành lại non sông gấm vóc của Tố quốc, song chưa có đường lối đúng đắn nên thất bại, quần chúng cách mạng bị dìm trong biển máu. Con đường cứu nước theo tư tưởng của cụ Phan Chu Trinh là dựa vào Pháp để thực hiện khẩu hiệu "Chân dân khí, khai dân khí, hậu dân sinh" chẳng khác gì cầu mong giặc Pháp rủ lòng thương. Cụ Phan Bội Châu áp dụng phương pháp "dĩ ngoại đột nội", dựa vào Nhật để đánh đuổi thực dân Pháp, có khác nào "đuổi hổ cửa trước và rước beo cửa sau". Người anh hùng áo vải Hoàng Hoa Thám dựä vào núi rừng Yên Thế kêu gọi quần chúng nổi dậy, dùng vũ trang đấu tranh chống Pháp, song chưa có phương pháp chính xác, chưa có lối thoát rõ ràng nên cuộc khởi nghĩa đã thất bại.

Đã đến lúc cần phải có một tư duy mới, vượt lên trên hạn chế của các nhà yêu nước đương thời mới có thể giải đáp được bài toán về con đường cách mạng đang được đặt ra. Sinh ra trong cảnh nước mất, nhà tan, lòng yêu nước, thương dân đã thôi thúc người thanh niên Nguyễn Tất Thành ra đi tìm đường cứu nước. Suốt hơn 10 năm lăn lộn, tìm tòi và thử nghiệm đã giúp Người hiểu rõ về những cuộc cách mạng đã và đang diễn ra trong thế giới hiện tại. Trong tác phẩm "Đường cách mệnh", sau khi phân tích cách mạng Mỹ, cách mạng Pháp, cách mạng Nga, Người cho rằng: "... Chỉ có cách mệnh Nga là đã thành công, và thành công đến nơi"(1). Người rút ra kết luâan là phải học tập cách mạng Nga. Cũng như sau khi được tiếp xúc "Bản luận cương về vấn đề dân tộc và thuộc địa" của Lê-nin, Người sung sướng nói to lên như đang nói trước quần chúng đông đảo "Hỡi đồng bào bị đọa đầy đau khổ! Đây là cái cần thiết cho chúng ta, đây là con đường giải phóng chúng ta!"(2). Người rút ra nhận xét : "Bây giờ học thuyết nhiều, chủ nghĩa nhiều, nhưng chủ nghĩa chân chính nhất, chắc chắn nhất, cách mệnh nhất là chủ nghĩa Lê-nin"(3). Người cảm nhận được ở chủ nghĩa Lênin sự thống nhất giữa "cẩm nang" thần kỳ cho hành động cách mạng và lòng thương yêu con người lao động.

Nếu từ lòng yêu nước, thương dân thúc giục Người ra đi tìm đường cứu 
nước, cứu dân thì đến với Cách mạng tháng Mười và chủ nghĩa Lê-nin, Người đã tìm thấy ở đó con đường cứu nước, cứu dân và giải phóng lao động. Người khẳng định : "Muốn cứu nước và giải phóng dân tộc không có con đường nào khác con đường cách mạng vô sản"(4)

Lựa chọn con đường cách mạng vô sản là sự thống nhất giữa điều kiện khách quan với nhận thức và hoạt động chủ quan của Hồ Chí Minh. Đó là sự gặp gỡ của thời đại và Hồ Chí Minh, đồng thời cũng là đóng góp to lớn nhất của Người với thời đại, đặc biệt là đối với các nước thuộc địa và phụ thuộc. Đi theo con đường cách mạng vô sản, chủ nghĩa nhân đạo ở Người vươn xa hơn, có sự chuyển biến về chất và trở thành chủ nghĩa nhân đạo cộng sản. Chủ nghĩa nhân đạo đó tiềm ẩn trong cách mạng giải phóng dân tộc khỏi ách nô dịch của chủ nghĩa thực dân, giải phóng quần chúng lao động khỏi áp bức bóc lột và đi đến mục tiêu cao cả của chủ nghĩa cộng sản là giải phóng con người. Thực hiện thắng lợi mục tiêu ấy thuộc về sứ mệnh lịch sử của giai cấp công nhân Việt Nam. Đó cũng là sự thống nhất sâu sắc giữa tính chính trị và tính nhân văn trong con đường cách mạng mà Chủ tịch Hồ Chí Minh đã lựa chọn.

Sự thống nhất giữa tính chính trị và tính nhân văn trong con đường cách mạng của Người còn thể hiện ở chỗ nó đã giải quyết đúng đắn mối quan hệ giữa lợi ích dân tộc với lợi ích giai cấp, giữa lợi ích quốc gia và lợi ích quốc tế, cốt lõi và xuyên suốt là độc lập dân tộc gắn liền với chủ nghĩa xã hội. Sự thống nhất ấy diễn ra trong suốt quá trình cách mạng, ở mỗi giai đoạn của cách mạng; thống nhất ở mục tiêu trước mắt cũng như lâu dài. Bởi đối với một dân tộc đã phải trải qua một ngàn năm đô hộ của phong kiến phương Bắc và gần một trăm năm dưới gót sắt của chủ nghĩa thực dân thì khát vong cao nhất và trực tiếp nhất là giành độc lập dân tộc, giải phóng dân tộc, giải phóng giai cấp và toàn thể nhân dân lao động thoát khỏi mọi áp bức giai cấp, nô dịch dân tộc. Nhưng để có độc lập thực sự cho dân tộc phải đi lên chủ nghĩa xã hội. Vì vậy, độc lập dân tộc phải gắn liền với chủ nghĩa xã hội. Độc lập dân tộc là mục tiêu, lý tưởng của chủ nghĩa xã hội, là điều kiện tiên quyết để thực hiện chủ nghĩa xã hội. Xây dựng chủ nghĩa xã hội thực sự đem lại cuộc sống ấm no, tự do, hạnh phúc cho nhân dân là nhân tố cơ bản đảm bảo vững chắc cho nền độc lập dân tộc. Hồ Chủ tịch đã từng nói: "Nhưng nếu nước được độc lập mà dân không hưởng hạnh phúc tự do, thì độc lập cũng chẳng có nghĩa lý gì"(5). Và "Dân chỉ biết rõ giá trị của tự do, của độc lập khi mà dân được ăn no, mặc đủ"(6). Như thế nghĩa là cách mạng Việt Nam phải hướng tới mục tiêu giải phóng dân tộc, giải phóng giai cấp, giải phóng con người thoát khỏi mọi áp bức, bóc lột và bất công, tiến tới một xã hội "trong đó sự" phát triển tự do của mỗi người là điều kiện cho sự phát triển tự do của tất cả mọi người"(7). Chính vì vậy, trong "Chính cương vắn tắt", Người chủ trương tiến hành tư sản dân quyền cách mạng và thổ địa cách mạng (cách mạng dân tộc dân chủ nhân dân sau này) để đỉ tới xã hội cộng sản.

Ngay trong cách mạng dân tộc dân chủ nhân dân, Người cũng xác địinh cần phải giải quyết hai nội dung cơ bản đó là: độc lập dân tộc và dân chủ nhân dân. Trong đó độc lập dân tộc là nhu cầu bức thiết cần phải tập trung sức lực giải quyết. Bởi mâu thuẫn giữa đế quốc xâm lược với nhân dân ta mà đông đảo là công nhân và nông dân là mâu thuẫn bao trùm tất cả, còn phong kiến chỉ là 
tay sai và chịu sự chi phối của thực dân đế quốc. Mâu thuẫn này nổi lên sâu sắc, gay gắt, đòi hỏi phải giải quyết. Ngay từ khi thực dân Pháp xâm lược nước ta, nhiệm vụ giải phóng dân tộc chống đế quốc Pháp và tay sai đã là sự nghiệp nổi lên hàng đầu của nhân dân Việt Nam, cách mạng Việt Nam. Đặt lên hàng đầu nhiệm vụ giải phóng dân tộc không có nghĩa là coi nhẹ vấn đề giai cấp, coi nhẹ chủ nghĩa xã hội và Hồ Chí Minh cũng không chỉ dùng lại ở người anh hùng giải phóng dân tộc như một số người đề cập. Trái lại, Người luôn quan niệm độc lập dân tộc là mục tiêu trước tiên phải giành được để tiến lên chủ nghĩa xã hội. Tuy trong cách mạng dân tộc dân chử nhân dân, nhất là ở giai đoạn đấu tranh giành chính quyền, chủ nghĩa xã hội mới chỉ là mục tiêu, nhưng nó chỉ rõ phương hướng đi lên của cách mạng Việt Nam = một cuộc cách mạng do Đảng Cộng sản, đội tiên phong của giai cấp công nhân Việt Nam lãnh đạo. Chính vì vậy, sau mối bưởc thắng lợi của cách mạng giải phóng dân tộc, Người luôn quan tâm phát triển kinh tế, văn hóa, xã hội, xây dựng lực lượng cách mạng đi đôi với củng cố chính quyền cách mạng. Đường lối vừa kháng chiến, vừa kiến quốc thực sự đóng vai trò to lớn vào sự nghiệp giải phóng dân tộc và tạo lập chế độ mới trong cách mạng dân tộc dân chủ nhân dân. Bường lối đó là cơ sở cho tiến hành đồng thời hai nhiệm vụ chiến lược cách mạng, cách mạng giải phóng dân tộc ở miền Nam và cách mạng xã hội chủ nghĩa ở miền Bắc giai đoạn 19541975, cũng như thực hiện hai nhiệm vụ chiến lược xây dựng chủ nghĩa xã hội và bảo vệ Tổ quốc trên phạm vi cả nước sau này.

Độc lập dân tộc không chỉ là khẩu hiệu mà phải thực sự độc lập hoàn toàn, phải gắn liền với thống nhất tổ quốc, Nam - Bắc một nhà. Độc lập bao giờ cũng gắn liền với tự do dân chủ và ấm no hạnh phúc của nhân dân. Dân chủ cũng là nhu cầu không thể thiếu được đối với một nước thuộc địa, nửa phong kiến có trên $90 \%$ là nông dân. Dân chủ trước hết !úc này là phải giành lại ruộng đất cho dân cày và xác định quyền làm chủ của nông dân trên đồng ruộng của họ. Đó cũng là quyền làm chủ của nhân dân lao động trên tất cả các lĩnh vực : nhân quyền, tài quyền, dân quyền và bình quyền.

Độc lập dân tộc và dân chủ là hai mục tiêu cơ bản, hai nội dung lớn mà cách mạng dân tộc dân chủ nhân dân phải thực hiện. Hai nội dung đó quan hệ chặt chẽ và thúc đẩy nhau, song trước hết cần tập trung vào độc lập dân tộc vì nó giải quyết mâu thuẫn chủ yếu giữa toàn thể nhân dân ta với đế quốc xâm lược. Giải quyết mâu thuẫn này cũng là thực hiện được hai mâu thuẫn cơ bản của xã hội thuộc địa nửa phong kiến.

Tư tưởng Hồ Chí Minh về con đường cách mạng Việt Nam là tư tưởng cách mạng không ngừng, là sự thống nhất giửa độc lập dân tộc, dân chủ và chủ nghĩa xã hội. Vì vậy, chủ nghĩa xã hội là con đường phát triển tất yếu của cách mạng dân tộc dân chủ nhân dân do Đảng Cộng sản lãnh đạo, sau khi đã căn bản thực hiện thắng lợi các mục tiêu trong cách mạng dân tộc dân chủ nhân dân. Đó là sự lựa chọn của Hồ Chí Minh, của nhân dân Việt Nam và của chính lịch sử những năm đầu thế kỷ $X X$. Người chỉ rõ : "Chỉ có chủ nghĩa cộng sản mới cứu nhân loại, đẹm lại cho mọi người không phân biệt chủng tộc và nguồn gốc sự tự do, bình đẳng, bác ái, đoàn kết, ấm no trên quả đất, việc làm cho mọi người và vì mọi người, niềm vui, hòa bình, hạnh phúc..." $(8)$. 
Nhưng do xuất phát từ đặc điểm của thực tiễn xã hội Việt Nam, một nước nông nghiệp lạc hậu, thuộc địa, nửa phong kiến bỏ qua chế độ tư bản chủ nghĩa, quá độ lên chủ nghĩa xã hội, nên trong quan niệm về chủ nghĩa xã hội là làm sao cho dấn giàu, nước mạnh, ai cũng có cơm ăn, ai cũng có áo mặc, ai cũng được học hành. Dân giàu và nước mạnh có mối quan hệ biện chứng với nhau. Dân có giàu thì nước mới mạnh, sự phồn vinh của đất nước và chế độ không thể tách rời tự do, ấm no, hạnh phúc của nhân dân. Sức hấp dẫn về chủ nghĩa xã hội trong tư tưởng của Người không phải là chỗ đưa ra những ý tưởng trừu tượng, cao xa mà là những lợi ích rất cụ thể thiết thực, gần gũi với những nhu cầu đời thường của nhân dân lao động. Những quan niệm về chủ nghĩa xã hội được diễn đạt rất dễ hiểu, dễ đi vào lòng người và cổ vũ họ đấu tranh giành độc lập dân tộc, dân chủ cho nhân dân và hướng tới chủ nghĩa xã hội.

Để quần chúng dễ hiểu về chủ nghĩa xã hội, Người giải thích rõ : "Chủ nghĩa xã hội là làm sao cho nhân dân đủ ăn, đủ mặc, ngày càng sung sướng, ai nấy được đi học, ốm đau có thuốc, già không lao động được thì nghî, những phong tục tập quán không tốt dần dần được xóa bỏ (...). Tóm lại, xã hội ngày càng tiến, vật chất ngày càng tăng, tinh thần ngày càng tốt, đó là chủ nghĩa xã hội"(9). Như vậy, có thể khẳng định rằng tư tưởng về chủ nghĩa xã hội của Người thể hiện đậm nét sự công bằng xã hội. Nó không chỉ phản ánh mục tiêu, lý tưởng, bản chất sứ mệnh lịch sử của giai cấp công nhân Việt Nam mà còn chứa đựng nội dung nhân đạo, nhân văn sâu sắc. Đó là chủ nghĩa xã hội tất cả vì con người và do con người.

Trung thành với con đường đã chọn, suốt cuộc đời Hồ Chí Minh đã phấn đấu không mệt mỏi cho sự nghiệp giải phóng dân tộc, giải phóng giai cấp, giải phóng xã hội và giải phóng con người, vì một xã hội nhân đạo, hiện thực trên đất nước Việt Nam.

Trong tình hình hiện nay, chủ nghĩa xã hội thế giới vẫn đang ở vào giai đoạn thoái trào, lý tưởng xã hội chủ nghĩa và sự lựa chọn con đường chủ nghĩa xã hội đang đứng trước sự dè bỉu chưa từng thấy từ nhiều hướng. Ngay một bộ phận nhân dân ta, trong đó có cả những cán bộ, đảng viên đã một thời không tiếc máu xương cho sự nghiệp giải phóng dân tộc, nhưng đứng trước những khó khăn trong thời kỳ quá độ lên chủ nghĩa xã hội, những tác động tiêu cực của cơ chế thị trường kết hợp với sự chống phá quyết liệt của kẻ thù, đã mất phương hướng chính trị, dao động về lập trường tư tưởng. Thậm chí có người phủ nhận những thành quả cách mạng mà nhẩn dân ta giành được, cho rằng chúng ta tiến hành kháng chiến chống Pháp và chống Mỹ là sai lầm, gây nên sự mất mát hy sinh không cần thiết... Trong điều kiện nền kinh tế hàng hóa nhiều thành phần và cơ chế thị trường ở nước ta hiện nay, một số người còn cho rằng đã là nền kinh tế hàng hóa nhiều thành phần thì phải tự do hóa, chế độ một đảng lãnh đạo là không tương dung với kinh tế nhiều thành phần, hoặc đã chấp nhận kinh tế thị trường thì đừng nói đến định hướng xã hội chủ nghĩa. Từ đó, họ khuyên chúng ta không nên tiếp tục con đường xã hội chủ nghĩa mà nên đỉ theo chủ nghĩa xã hội dân chủ hay dừng lại ở chế độ dân chủ nhân dân, củng cố chế độ dân chủ nhân dân đến khi nào chuẩn bị đầy đủ các yếu tố hãy đi lên chủ nghĩa xã hội cũng chưa muộn, v.v...

Những quan niệm ấy tuy đề cập ở lúc này, lúc khác, mức độ này hay mức độ 
khác, nhưng thực chất là phủ nhận con đường xã hội chủ nghĩa mà Chủ tịch Hồ Chí Minh đã lựa chọn. Vì vậy, càng đứng trước những biến động của tình hình, càng đòi hỏi chúng ta phải vững tin vào con đường Bác Hồ đã lựa chọn, giữ vững mục tiêu độc lập dân tộc và chủ nghĩa xã hội trong quá trình đổi mới, ra sức thực hiện hai nhiệm vụ chiến lược xây dựng chủ nghĩa xã hội và bảo vệ Tổ quốc xã hội chủ nghĩa, vì dân giàu, nước mạnh, xã hội công bằng, dân chủ, văn minh.

\section{CHÚ THÍCH:}

(1), (3) Hồ Chí Minh, Toàn tập, tập 2, Nxb Chính trị quốc gia, Hà Nội, 1995, $\operatorname{tr} .280,268$. $\operatorname{tr} .127,314$.

(2), (4) Hồ Chí Minh, Toàn tập, tập 10, Nxb Chính trị quốc gia, Hà Nội, 1996, $\operatorname{tr} .56,152$.

(5), (6) Hồ Chí Minh, Toàn tập, tập 4, Nxb Chính trị quốc gia, Hà Nội, 1995,

(7) C.Mác và Ph.Ăng nghen, Toàn tập, tập 4, Nxb Chính trị quốc gia, Hà Nội, 1995, tr.628.

(8) Hồ Chí Minh, Toàn tập, tập 1, Nxb Chính trị quốc gia, Hà Nội, 1995, tr.461.

(9) Hồ Chí Minh, Toàn tập, tập 10, Nxb Chính trị quốc gia, Hà Nội, 1996, tr.591.

\section{TÓM TẮT}

Tư tưởng Hồ Chí Minh về con đường cách mạng Việt Nam là tư tưởng cách mạng không ngừng, là sự thống nhất giữa độc lập dân tộc, dân chủ và chủ nghĩa xã hội. Vì vậy, chủ nghĩa xã hội là con đường phát triển tất yếu của cách mạng Việt Nam do Đảng Cộng sản lãnh đạo.

\section{SUMMARY}

Ho Chi Minh Ideology on the Vietnamese revolutionary road is the ceaseless revolutionary ideology, the unification of independence, democracy, and socialism. therefore, socialism is the requisite development road of the Vietnamese revolution led by the Communist Party. 